\title{
Desain Furnitur untuk Kamar Asrama Mahasiswa Studi Kasus: Gedung Single Blok Asrama Mahasiswa ITS
}

\author{
Mohamad Rizal Amiruddin dan Taufik Hidayat \\ Departemen Desain Produk Industri, Fakultas Teknik Sipil dan Perencanaan, Institut Teknologi \\ Sepuluh Nopember (ITS) \\ e-mail: zota@prodes.its.ac.id
}

\begin{abstract}
Abstrak-Institut Teknologi Sepuluh Nopember (ITS) Surabaya merupakan salah satu perguruan tinggi terbaik di Indonesia (Dikti, 2015). Hal ini berbanding lurus dengan jumlah peminat pelajar yang ingin menuntut ilmu di ITS. Mahasiswa ITS berasal dari berbagai daerah diseluruh Indonesia, dan juga luar negeri. Mahasiswa yang berdomisili diluar daerah Surabaya membutuhkan tempat tinggal sementara. Permasalahan utama pada kamar asrama mahasiswa ITS ialah pengorganisasian barang dan masalah privasi antar penghuni kamar. Tujuan dari perancangan desain furnitur kamar asrama mahasiswa ITS ini ialah menghasilkan desain furnitur kamar asrama yang mampu memenuhi permasalahan pengguna. Langkah ataupun metode yang dilakukan antara lain interview, shadowing, dan affinity diagram. Hasil dari metode penelitian tersebut bertujuan untuk mengetahui masalah yang ada dikamar asrama agar mendapatkan ide - ide tentang fitur furnitur kamar asrama yang sesuai dengan kebutuhan. Dari metode yang dilakukan menghasilkan konsep desain furnitur organized, dan personal space. Hasil dari penelitian ini adalah tempat tidur yang terintegrasi dengan meja belajar dan lemari kebutuhan penghuni asrama.
\end{abstract}

Kata Kunci- asrama, furnitur, organized, personal space.

\section{PENDAHULUAN}

I NSTITUT Teknologi Sepuluh Nopember(ITS) Surabaya merupakan salah satu perguruan tinggi terbaik di Indonesia (Dikti, 2016). Hal tersebut berbanding lurus dengan jumlah peminat yang menuntut ilmu di ITS. Mahasiswa yang berdomisili diluar daerah Surabaya membutuhkan tempat tinggal sementara. Asrama Mahasiswa ITS merupakan salah satu tempat tinggal sementara yang paling diminati oleh mahasiswa baru ITS. Selain karena harga yang lebih terjangkau, akses menuju kampus ITS yang mudah menjadi alasan diminatinya asrama mahasiswa ini. Tercatat dari jumlah mahasiswa baru yang mencapai 1.607 , lebih dari 50 persen memilih untuk tinggal di asrama mahassiwa ITS(Unit Asrama ITS, 2015).

Asrama mahasiswa ITS didirikan untuk wadah interaksi sosial yang baik agar tercipta rasa kebersamaan, kedisiplinan diri, maupun keamanan dari setiap penghuni asrama. Dalam lokasi asrama mahasiswa ITS terbagi menjadi 2 tipe gedung asrama, antara lain:

\section{A. Gedung tipe single blok}

Dalam asrama mahasiswa ITS terdapat 4 gedung tipe single blok. Terdiri dari 3 jenis ruang kamar dengan jumlah total 136 kamar, yaitu kamar 1 orang, kamar 2 orang, dan kamar 4 orang.

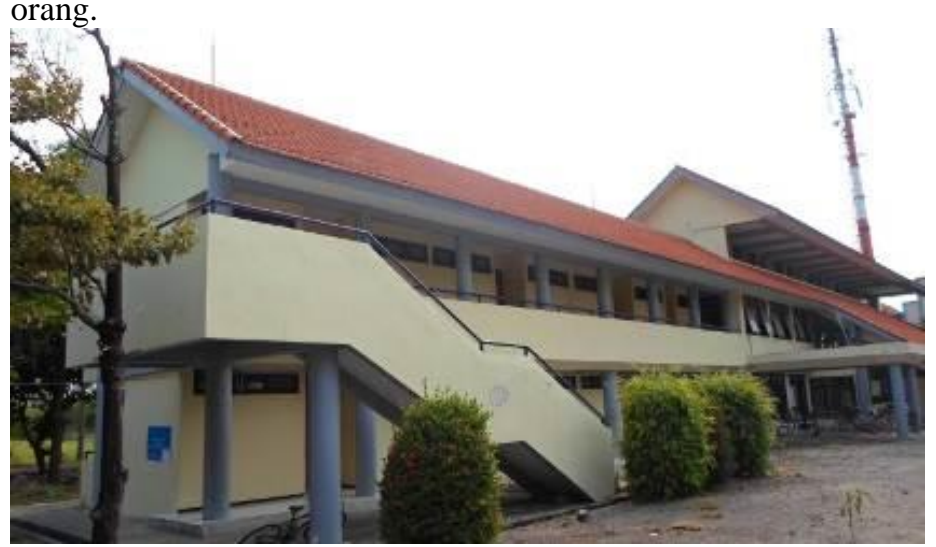

Gambar 1. Gedung tipe single blok.

\section{B. Gedung tipe twin blok}

Dalam asrama mahasiswa ITS terdapat 4 gedung tipe twin blok. Terdiri dari satu jenis ruang kamar dengan jumlah total 384 kamar. Setiap kamar ditempati oleh 2 orang.

Dari riset yang telah dilakukan sebelumnya, didapatkan aspek perilaku penghuni asrama di asrama mahasiswa ITS. Parameter diambil dari buku Designing Place for People untuk mengetahui seberapa besar masalah yang terjadi. Berikut tabel aspek perilaku beserta penilaiannya:

Tabel 1.

Perbandingan kamar gedung single blok dan twin blok

\begin{tabular}{cccccc}
\hline $\begin{array}{c}\text { Tipe } \\
\text { Gedung }\end{array}$ & Privacy & Safety & Disiplin & $\begin{array}{c}\text { Kebersa } \\
\text { maan }\end{array}$ & $\begin{array}{c}\text { Kebers } \\
\text { ihan }\end{array}$ \\
\hline $\begin{array}{c}\text { Twin blok } \\
\text { (2 orang) }\end{array}$ & Sedang & Sedang & Sedang & Rendah & Sedang \\
Single blok & Rendah & Rendah & Rendah & Tinggi & Rendah \\
$(4$ orang $)$ & & & & & \\
\hline
\end{tabular}


Pada tabel diatas dapat disimpulkan bahwa gedung tipe single blok dengan jenis kamar 4 orang mempunyai masalah yang lebih tinggi dibanding lainnya. Oleh karena itu, diperlukan solusi untuk dapat mengatasi masalah tersebut.

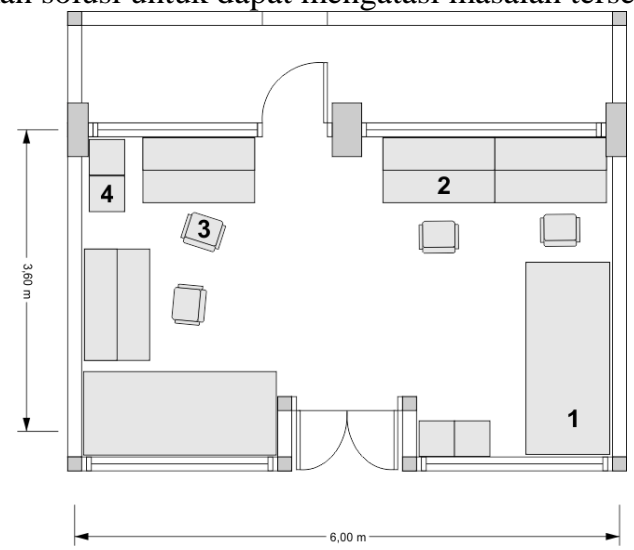

Gambar 2. Denah kamar 4 orang tipe single blok dengan dimensi 6 x 3,6m.

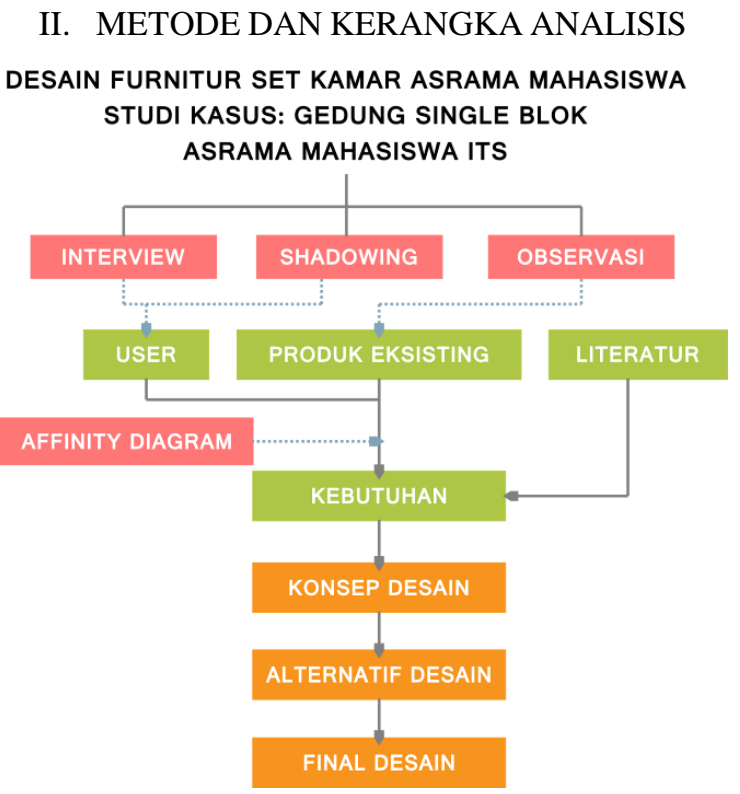

Bagan 1. Langkah metode penelitian yang dilakukan dalam proses final desain terpilih.

\section{A. Subjek dan Objek}

Subjek Perancangan : organized dan personal space furnitur untuk kamar asrama mahasiswa. Objek Perancangan

1. Tempat tidur

2. Meja Belajar

3. Lemari pakaian

4. Storage barang - barang kebutuhan

\section{B. Interview}

Interview merupakan metode riset dimana penulis mewawancarai user, antara lain penghuni asrama dan pengelola asrama mahasiswa ITS. Hasil dari metode interview untuk penghuni asrama adalah aktivitas, perilaku, dan kebutuhan sat dikamar asrama. Sedangkan hasil dari pengelola asrama adalah mendapatkan data yang berkaitan dengan asrama mahasiswa ITS.

\section{Shadowing}

Teknik shadowing merupakan sebuah metode riset dimana penulis mengikuti aktivitas penghuni kamar pada saat didalam kamar asrama. Hasil dari metode ini adalah untuk menganalisis aktivitas penghuni kamar asrama dan mendapatkan kebutuhan yang tidak disadari (hidden needs).

\section{Observasi}

Observasi merupakan metode riset dimana penulis melakukan pengamatan secara langsung pada kamar asrama mahasiswa ITS dan produk eksisting yang digunakan . Hasil yang didapat ialah detail dimensi dari kamar asrama dan produk eksisting. Penulis juga mendapatkan data tentang kelebihan maupun kekurangan produk eksisting pada target perancangan.

\section{E. Affinity Diagram}

Artikel yang siap untuk dipublikasikan harus dilengkapi dengan sebuah formulir copyright. Anda dapat mendapatkan formulir ini di http://ejurnal.its.ac.id/. Setiap penulis bertanggung jawab secara pribadi untuk mendapatkan security clearances apapun yang dibutuhkan.

\section{STUDI DAN ANALISIS}

\section{A. Konsep Desain}

Konsep desain mengacu pada kata kunci desain yang diperoleh dari metode penelitian affinity diagram.

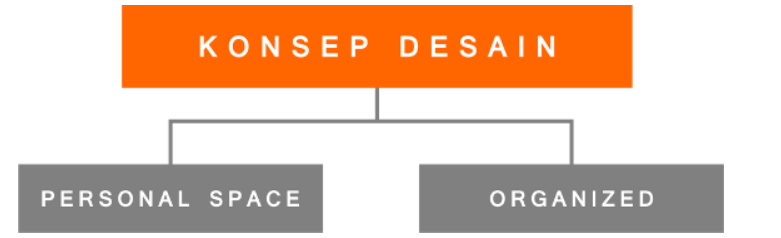

Bagan 2. Konsep desain yang diperoleh dari metode penelitian affinity diagram.

1. Personal Space, membagi ruangan menjadi empat bagian yang bertujuan untuk menjaga teritori setiap individu dalam setiap ruang.

2. Organized, merancang sebuah furnitur yang terintegrasi dan terorganisir agar penghuni kamar dapat beraktivitas lebih efisien. Tujuannya untuk membagi ruang agar dapat menampung keseluruhan furnitur sehingga tertata rapi.

\section{B. Alternatif Desain}

Alternatif desain berupa 3D rendering yang berdasar pada konsep dan fungsi desain.

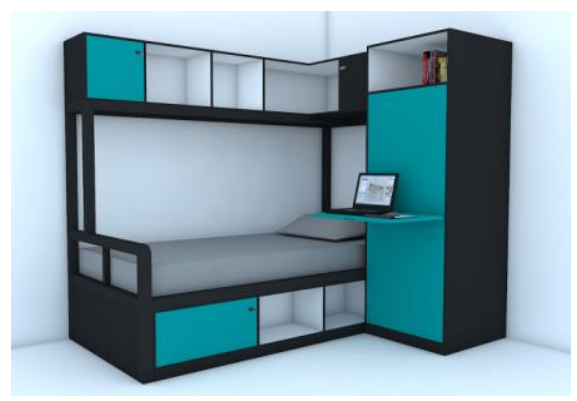

Gambar 3. Alternatif desain 1. 


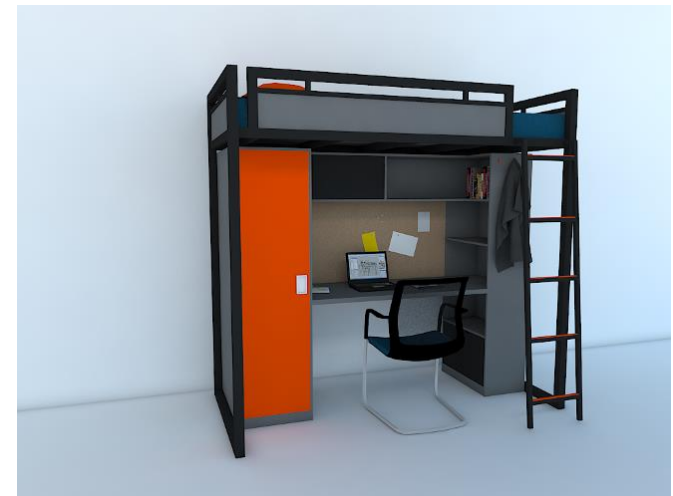

Gambar 4. Alternatif desain 2.

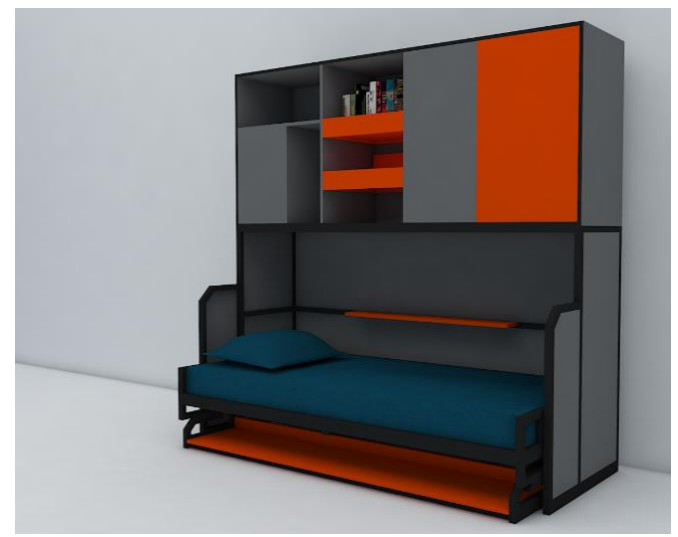

Gambar 5. Alternatif desain 3.

Dari hasil parameter penilain final desain diatas, alternatif 3 adalah desain yang paling memenuhi kriteria desain.

\section{HASIL DESAIN DAN PEMBAHASAN}

\section{A. Final Desain}

Melalui Tabel 2-3 didapatkan satu final desain, dengan fungsi memenuhi seluruh kebutuhan furnitur penghuni asrama mahasiswa, antara lain: tempat tidur, meja belajar, lemari pakaian, rak buku, rak alas kaki, dan rak kebutuhan pribadi lainnya.

Tabel 2.

Keterangan skor penilaian

\begin{tabular}{cl}
\hline Skor & \multicolumn{1}{c}{ Keterangan } \\
\hline 1 & Baik sekali \\
2 & Baik \\
3 & Cukup \\
4 & Kurang \\
5 & Kurang sekali \\
\hline \hline
\end{tabular}

Tabel 3.

Parameter penilaian final desain

\begin{tabular}{lccc}
\hline \hline \multicolumn{1}{r}{ Parameter } & Alt 1 & Skor \\
Alt 2 & Alt 3 \\
\hline Organized storage & 4 & 5 & 5 \\
Efisiensi ruang & 3 & 4 & 5 \\
Privacy & 4 & 4 & 4 \\
Kemudahan akses & 4 & 3 & 4 \\
Kenyamanan belajar & 3 & 4 & 4 \\
Kenyamanan istirahat & 3 & 3 & 4 \\
Kemudahan produksi & 4 & 4 & 3 \\
\hline \hline
\end{tabular}

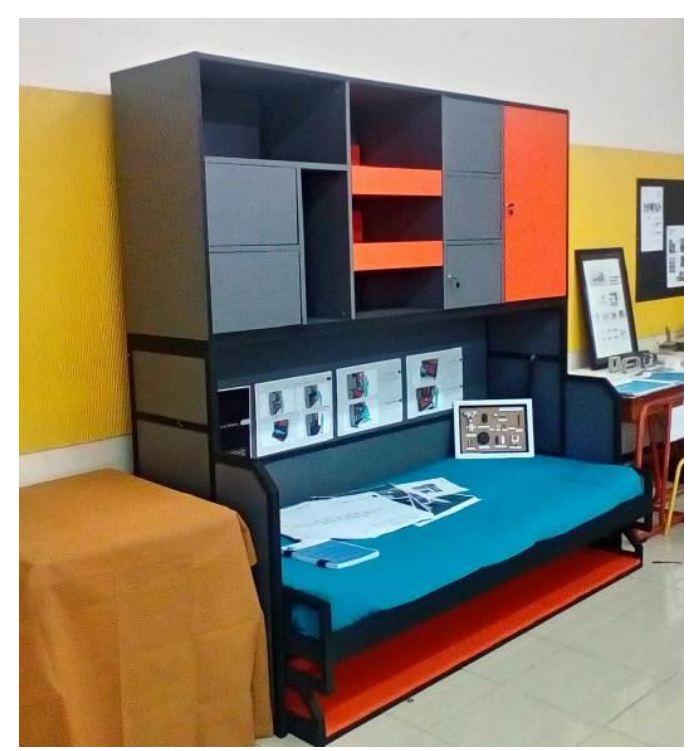

Gambar 6. Prototype desain final.

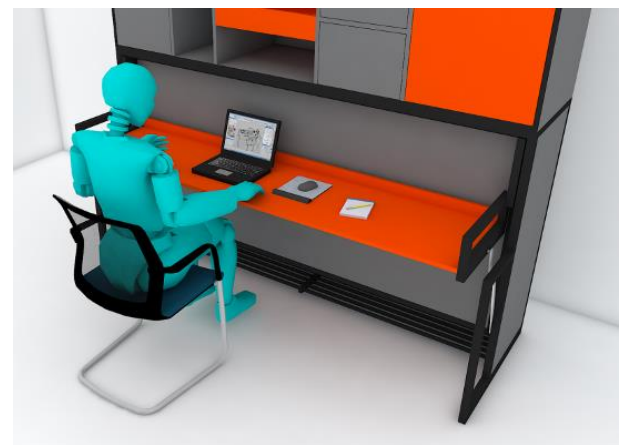

Gambar 7. Saat digunakan menjadi meja belajar.

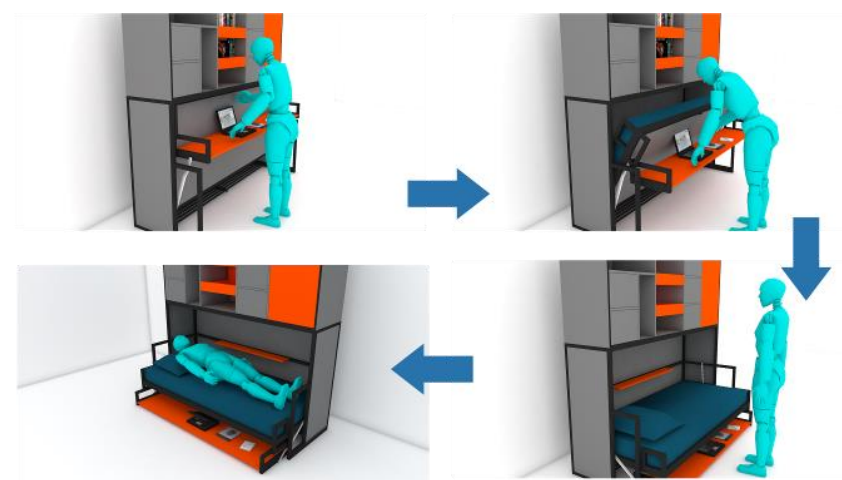

Gambar 8. Operasional dari meja belajar menjadi tempat tidur.

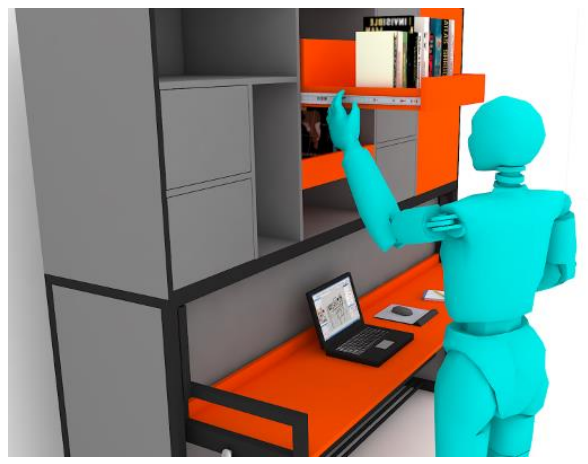

Gambar 9. Pengguna saat mengambil buku. 


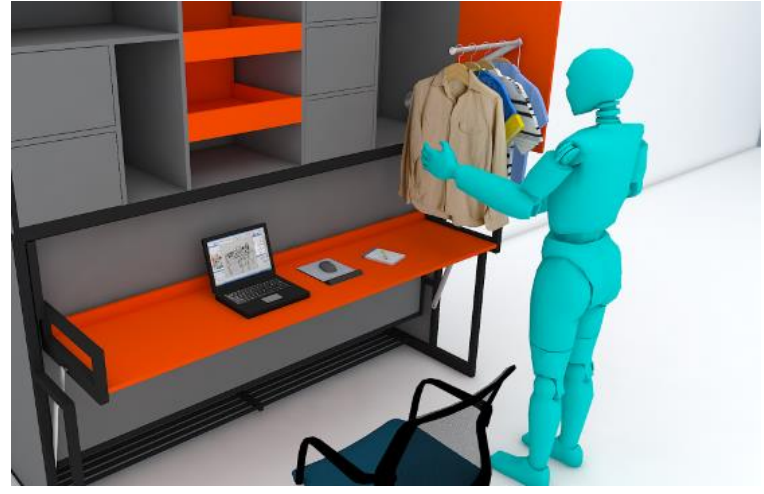

Gambar 10. Pengguna saat menyimpan baju.

\section{B. Aplikasi pada Layout}

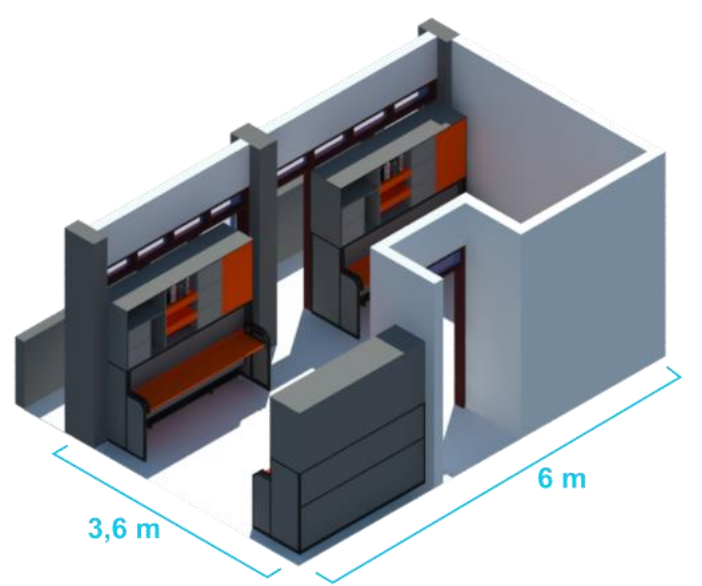

Gambar 11. Penempatan pada layout di ruang kamar asrama.

\section{KESIMPULAN}

1. Dimensi lemari pakaian 500 x 500 x 900 memenuhi kebutuhan tempat penyimpanan pakaian yang digantung. Sedangkan dimensi lemari pakaian 380 × 500 x 290 dapat memenuhi kebutuhan untuk menyimpan pakaian yang dilipat.

2. Free space pada atas tempat tidur membuat pengguna lebih aman dan lega pada saat bangun ataupun sedang duduk dibagian samping tempat tidur.

3. Dengan penggunaan konsep personal space, yaitu membagi ruangan menjadi empat bagian untuk menjaga teritori setiap individu dalam satu ruang. Hal tersebut membuat terseleksinya barang milik penghuni satu dengan lain agar keamanan lebih terjaga.

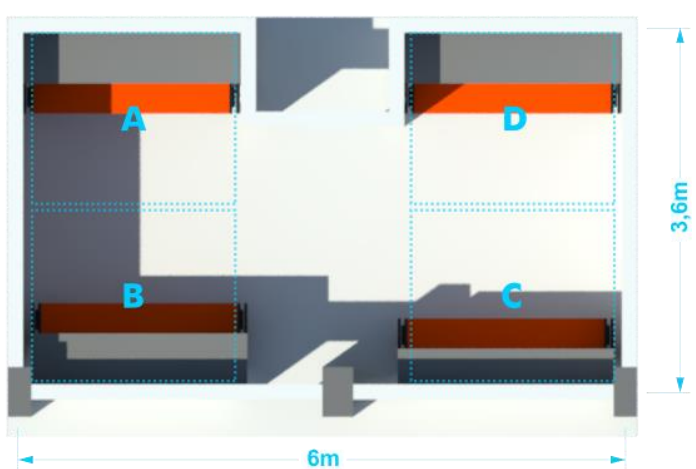

Gambar 12. Konsep personal space yang membagi ruang menjadi empat bagian untuk menjaga keamanan barang pribadi.

4. Pengguna dimudahkan dengan konsep storage yang organized,sebab hal tersebut membuat barang - barang dapat tertata dengan rapi pada setiap tempatnya.

5. Tersedianya rak alas kaki didalam kamar pada setiap furnitur membuat kamar terlihat lebih tertata dan rapi.

6. Kamar dengan dimensi $6 \times 3,6 \mathrm{~m}$ dan furnitur pada perancangan ini dengan dimensi 2110 x 800 x 2010 membuat area bebas yang luas, memudahkan penghuni kamar saat ingin beribadah didalam kamar.

\section{DAFTAR PUSTAKA}

[1] J. Efendi et al., "PENGARUH LINGKUNGAN KOS TERHADAP PRESTASI BELAJAR MAHASISWA PENDIDIKAN GEOGRAFI (STKIP) PGRI SUMATERA BARAT."

[2] A. F. Helmi, "BEBERAPA TEORI PSIKOLOGI LINGKUNGAN," Bul. Psikol., vol. 7, no. 2, Sep. 2015.

[3] S. Goldsmith, Universal Design: A Manual of Practical Guidance for Architects. Great Britain: Reed Educational and Professional Publishing, 2000.

[4] Häfele, Catalogues \&amp; brochures - Häfele. UK: Häfele.

[5] M. M. Astro, "Jumlah Pendatang Baru Surabaya Capai 100 Ribu ANTARA News Jawa Timur," Antara Jatim, 2013. [Online]. Available: https://jatim.antaranews.com/lihat/berita/115765/jumlahpendatang-baru-surabaya-capai-100-ribu. [Accessed: 22-Mar-2018].

[6] B. Martin, B. Hanington, and B. M. Hanington, Universal Methods of Design: 100 Ways to Research Complex Problems - - Google Books. Beverly, MA: Rockport Publisher, 2012.

[7] J. Panero and Z. Martin, Dimensi Manusia \& Ruang Interior. Jakarta: Erlangga, 2003.

[8] Pemerintah Kota Surabaya, "Home: Berita. Retrieved from Website Resmi Pemerintah Kota Surabaya," 2015. [Online]. Available: http://www.surabaya.go.id.

[9] H. Prabowo, "Arsitektur, Psikologi dan Masyarakat." Gunadarma, Jakarta, 1998.

[10] J. Suwito, "Kajian Pustaka." Universitas Pendidikan Indonesia, Bandung, 2003. 